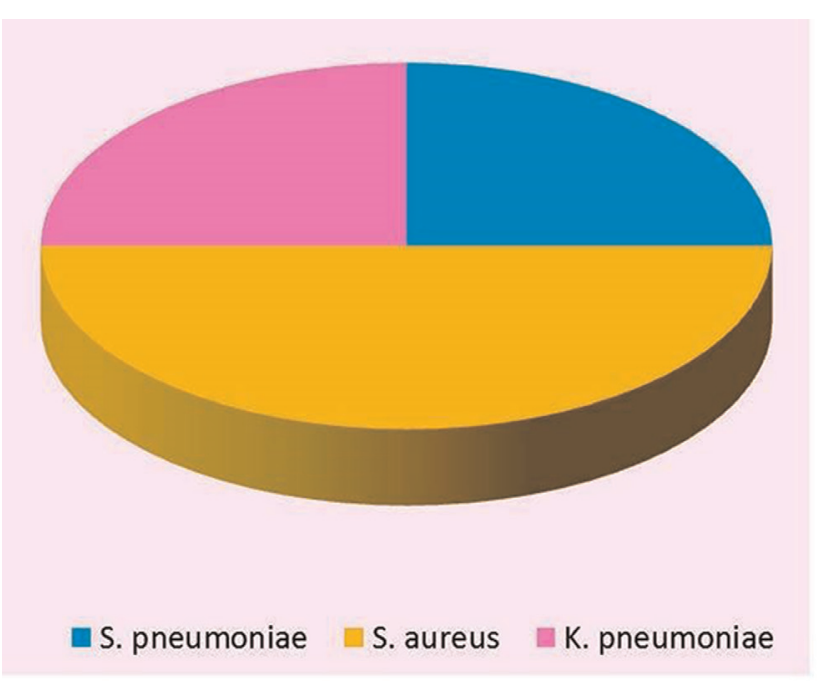

Blood culture $(n=4)$

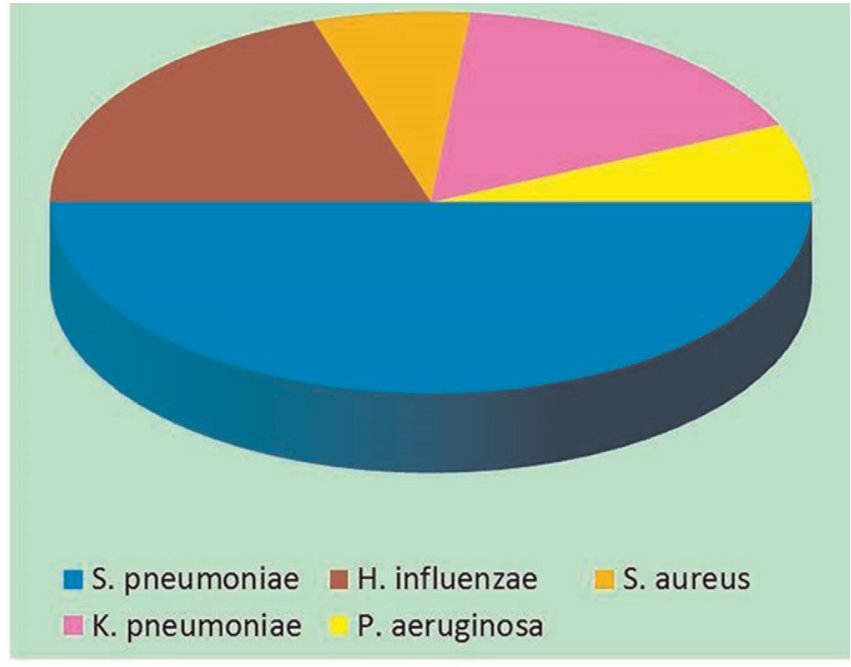

NPA culture $(\mathbf{n}=\mathbf{3 0})$

Abstract P0-0197 Figure 1 Bacteria detected by culture (Blood and NPA)

\section{PO-0197 BACTERIAL CULTURE VERSUS PCR FOR ETIOLOGIC DIAGNOSIS OF COMMUNITY ACQUIRED PNEUMONIA- RESULTS FROM CAPES (COMMUNITY ACQUIRED PNEUMONIA ETIOLOGY STUDY)}

1JL Mathew, 'S Singhi, ${ }^{2} \mathrm{P}$ Ray, ${ }^{3} \mathrm{BV}$ Ravi Kumar, ${ }^{1} \mathrm{~A}$ Bansal, ${ }^{4} \mathrm{~A}$ Nilsson. ${ }^{1}$ Advanced Pediatrics Centre, Post Graduate Institute of Medical Education and Research, Chandigarh, India; ${ }^{2}$ Medical Microbiology, Post Graduate Institute of Medical Education and Research, Chandigarh, India; ${ }^{3}$ Managing Director, Xcyton Diagnostics Pvt Ltd, Bangalore, India; ${ }^{4}$ Astrid Lindgren Children's Hospital, Karolinska University Hospital, Stockholm, Sweden

\subsection{6/archdischild-2014-307384.854}

Background PCR technologyholds promise to overcome the limitations of bacterial culture for confirming bacterial aetiology in childhood pneumonia.

Aims To compare the diagnostic yield using bacterial culture versus PCR in a cohort of children with community acquired pneumonia (CAP).

Methods CAPES is single-centre cohort study of 2000 consecutively enrolled children (1 month-12 years) with CAP(World Health Organisation definition). All underwent blood and

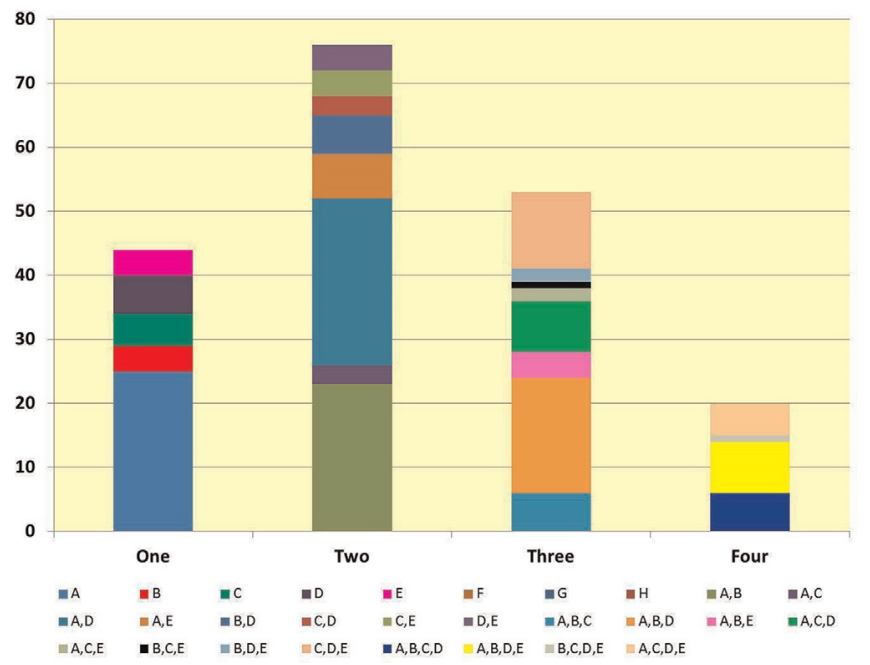

Abstract P0-0197 Figure 2 Bacteria detected by multiplex PCR nasopharyngeal aspirate (NPA) culture for bacteria. In addition, a randomly selected sub-group $(10 \%, \mathrm{n}=200)$ underwent multiplex PCR on NPA samples to identify eight pathogenic bacteria. Results In the sub-cohort of 200 children, pathogenic organisms were isolated from blood and NPA in 4(2\%) and $30(15 \%)$ respectively (Figure 1). The main cohort showed similar proportions $(1.7 \%$ and $14.0 \%)$ and distribution of organisms, suggesting absence of selection bias. Multiplex PCR(Figure 2) yielded traces of bacteria in 193(96.5\%), with one organism detected in $44(22 \%)$, two in $76(38 \%)$, three in $53(26.5 \%)$, and four in 20 (10\%). Etiologic diagnosis could be confirmed by bacterial culture in $4.5 \%$ cases, whereas PCR confirmed in $22 \%$.

Conclusion Bacterial culture techniques appear to have limited sensitivity for etiologic diagnosis, whereas PCR has much higher sensitivity, although detection of multiple pathogenic bacteria precluded confirmation of aetiology in the majority.

\section{PO-0198 FERRITIN AND SERUM IRON IN PAEDIATRIC FEBRILE ILLNESS}

${ }^{1}$ A Nasir, ${ }^{2}$ S James, ${ }^{3}$ D Perry, ${ }^{4}$ J Meza. ${ }^{1}$ Pediatrics, University of Nebraska Medical Center, Omaha, USA; ${ }^{2}$ Emergency, Children's Hospital and Medical Center, Omaha, USA; ${ }^{3}$ Pathology, Children's Hospital and Medical Center, Omaha, USA; ${ }^{4}$ Statistics, University of Nebraska Medical Center, Omaha, USA

\subsection{6/archdischild-2014-307384.855}

Introduction Ferritin is the major intracellular iron binding protein in the body. Serum ferritin is an inflammatory marker. Iron sequestration is one of the innate immune responses to infection. The goal of this research was to investigate the role of serum ferritin and serum iron as clinically useful markers of infection in the paediatric emergency department.

Methods Multiple inflammatory markers, including C-reactive protein, procalcitonin, and serum ferritin, and other iron studies were measured in 37 children, from 3 months through 8 years of age, presenting to the emergency department with temperature of $\geq 39$ degrees Celsius, and 38 patients in the same age group with non-febrile illness (controls). Patients with chronic inflammatory or rheumatologic conditions and those with renal or hepatic failure were excluded. 
Results Mean serum ferritin, and ferritin/iron ratio were significantly higher among febrile children when compared to controls. Mean serum iron levels were significantly lower among febrile patients and in the subgroup of children who had bacterial infections when compared with children who had viral infections and those who had a non-infectious illness.

Conclusion Serum iron and ferritin/iron ratio may be clinically useful markers for the differentiation of bacterial from viral infection in the emergency department. Further studies are needed to confirm our findings and to further explore the role of iron metabolism in paediatric infections.

\section{PO-0199 MICROSCOPIC OBSERVATION DRUGS SUSCEPTIBILITY (MODS): A PROMISING CULTURE-BASED ASSAY TO DIAGNOSING TUBERCULOSIS IN CHILDREN}

${ }^{1} \mathrm{H}$ Nataprawira, ${ }^{2}$ Parwati. ${ }^{1}$ Child Health, Faculty of Medicine Universitas Padjadjaran, Bandung, Indonesia; ${ }^{2}$ Clinical Pathology, Faculty of Medicine Universitas Padjadjaran, Bandung, Indonesia

\subsection{6/archdischild-2014-307384.856}

Background To confirming diagnosis tuberculosis (TB) in children is still challenging worldwide, particularly in low-resource settings. The Microscopic Observation Drug Susceptibility (MODS) is promising whilst this assay improved yield recovery of Mycobacterium tuberculosis that is faster and better as compared with traditional culture method. In Indonesia, MODS culture study in adults $\mathrm{TB}$ have been reported but not for childhood TB because of the cost.

Methods Gastric aspirate specimen were collected from 10 children aged $\leq 14$ years suspected has having severe TB admitted to paediatric ward Hasan Sadikin Hospital-Bandung-Indonesia in 2011 examined by acid-fast bacilli (AFB) and cultured by MODS in Department of Clinical Pathology. We presumed TB for those children who responded clinically at the end of their TB treatment. The outcome measurements were proportion of specimens that culture positive by MODS.

Results Eight of 10 children were preadolescents and adolescents age. All children were severe malnourished, but one. Tuberculous meningitis was diagnosed in $3 / 10$ children and others seven children diagnosed as spondylitis TB (1), destroyed lung TB (1), cutaneous TB (1), extensive pneumonic TB (4). All had positive AFB, but two. MODS provided significantly more positive cultures (8/10) and occurred in positive AFB children. Eight children were on directly-observed treatment shortcourse (DOTS).

Conclusion Isolation of Mycobacterium tuberculosis from severe TB children demonstrated greater yield by MODS culture assay and more frequent in preadolescent and adolescents children.

\section{PO-0200 SPHINGOMONAS PAUCIMOBILIS: A CAUSE OF OTOMASTOIDITIS COMPLICATED WITH SUBPERIOSTEAL ABSCESS IN AN IMMUNOCOMPETENT CHILD}

G Nuncio Benevides, N Hein, D Swei Lo, AE Ferronato, SLB Ragazzi, CRM Yoshioka, M Hirose, DM Cardoso, AE Gilio. Department of Pediatrics, University Hospital of University of Sao Paulo, São Paulo, Brazil

\subsection{6/archdischild-2014-307384.857}

We present the first case of Sphingomonas paucimobilis otomastoiditis, complicated with subperiosteal abscess in an immunocompetent child.

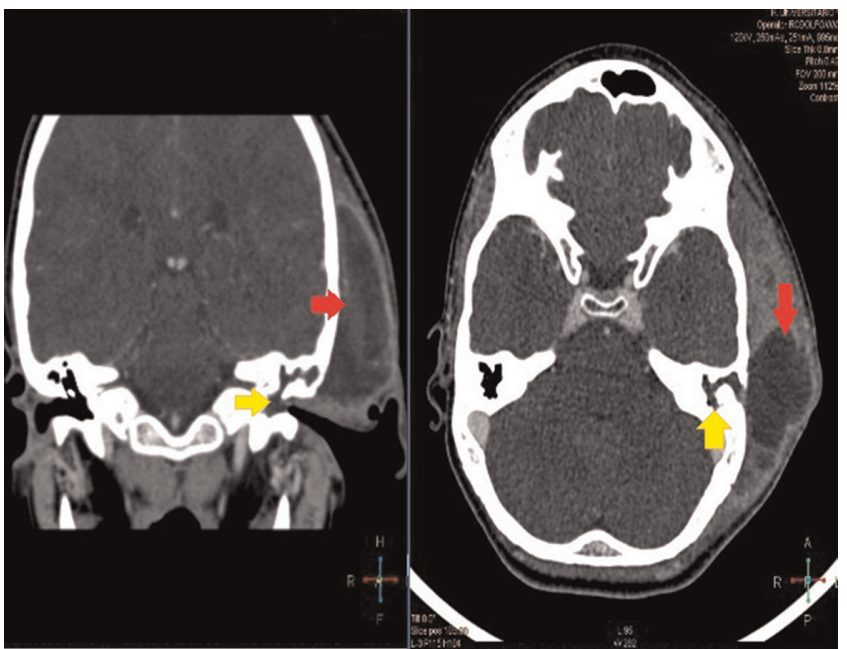

Abstract P0-0200 Figure 1 CT scan showing left otomastoiditis (yellow arrow) associated with a large collection exterior to the temporal bone (red arrow)

Case Report A 11-year-old boy with previous diagnosis of chronic bilateral otitis media presented with 20 days of fever, otalgia, otorrhea, progressive retroauricular swelling with protrusion of the left ear and worsening of the symptoms despite 15 days of Amoxicilin. A CT scan was performed (Figure 1). Blood tests showed WBC $22,4 \times 109$ (neutrophils $81,2 \%$ ) and CRP of 142. Surgical drainage of the abscess found a large amount of purulent foetid secretion. We empirically initiated Ceftazidime and Clindamycin. He remained well, with defervescence and resolution of the scalp deformation. Control test showed WBC 7,4 $\times 109$ (neutrophils 58,7\%) and CRP of 6. Culture of the abscess grew Sphingomonas paucimobilis. The patient was discharged with Cyprofloxacin and returned after 1 month in our clinic recovered.

Discussion S. paucimobilis is an aerobic gram-negative bacillus that rarely infects humans, most commonly immunocompromised and hospitalised patients. We searched the literature for $S$. Paucimobilis infections in children and found 47 reported cases (Table 1). The most common diagnosis is isolated bacteremia and there are no previous report of otomastoiditis. It is related to sporadic or epidemic infections, leading to just one published case of death in children. S. paucimobilis infection has been increasingly reported over the years and it's a more important pathogen than previously thought.

Abstract P0-0200 Table 1 Clinical characteristics of paediatric cases of Sphingomonas paucimobilis infection in our literature review

\begin{tabular}{|c|c|c|c|c|c|}
\hline Condition & $\begin{array}{c}\text { Number of } \\
\text { cases }\end{array}$ & $\begin{array}{c}\text { Mean Age } \\
\text { (range) }\end{array}$ & Gender & $\begin{array}{c}\text { Higid/Previous } \\
\text { Commorbity } \\
\text { (number of cases) }\end{array}$ & $\begin{array}{c}\text { Acquired Hospital / } \\
\text { Community } \\
\text { (number of cases) }\end{array}$ \\
\hline \multicolumn{6}{|c|}{ Isolated Bacteremia or } \\
\hline UII & 2 & $4,5 \mathrm{~m}(4-5 \mathrm{~m})$ & IM:IF & $2 / 0$ & $0 / 2$ \\
\hline CAPD Penitonitis & 1 & $14 \mathrm{y}$ & $0 \mathrm{M}: \mathrm{IF}$ & $0 / 1$ & $1 / 0$ \\
\hline Cervical Adenitis & 1 & $8 y$ & IM:OF & $1 / 0$ & $0 / 1$ \\
\hline $\begin{array}{l}\text { CNS Infection or } \\
\text { Abscess }\end{array}$ & 2 & $6-10 y$ & $1 \mathrm{M}: 1 \mathrm{~F}$ & $2 / 0$ & 1/1 \\
\hline $\begin{array}{l}\text { Osteomielitis/Septic } \\
\text { Arthritis }\end{array}$ & 1 & $16 y$ & $1 \mathrm{M}: 0 \mathrm{~F}$ & $0 / 1$ & ? \\
\hline Pneumonia & 1 & $5 y$ & IM:OF & $1 / 0$ & $0 / 1$ \\
\hline Otomastoiditis** & 1 & $11 \mathrm{y}$ & IM:OF & $1 / 0$ & $0 / 1$ \\
\hline Total & 47 & $5,3 y(0-17 y)$ & $1,7 \mathrm{M}: 1 \mathrm{~F}$ & $20 / 27$ & $27 / 19$ \\
\hline \multicolumn{6}{|c|}{ 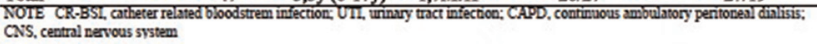 } \\
\hline \multicolumn{6}{|l|}{ - One case of death } \\
\hline \multicolumn{6}{|l|}{ *Present study } \\
\hline ? The author could not defin & if it was acqui & Ihenin & & & \\
\hline
\end{tabular}

